\title{
The potential for adoption of climate smart agricultural practices in Sub- Saharan livestock systems
}

\author{
Silvestre García de Jalón ${ }^{1 *}$, Silvia Silvestri ${ }^{2}$, Andrew P. Barnes ${ }^{3}$
}

(1) $\left({ }^{*}\right)$ School of Water, Energy and Environment, Cranfield University, Cranfield, MK43 OAL, UK (e-mail: s.garcia-de-jalon@cranfield.ac.uk) (Corresponding author)

(2) Center for Agriculture and Biosciences International (CABI), PO BOX 633-00621, Nairobi 00100, Kenya (e-mail: S.Silvestri@cabi.org)

(3) Scotland's Rural College, West Mains Road, Edinburgh EH9 3JG, UK (e-mail:

Andrew.Barnes@sruc.ac.uk)

\begin{abstract}
García de Jalón S, Silvestri S, Barnes A (in press) The potential for adoption of climate smart agricultural practices in Sub-Saharan livestock systems. Regional Environmental Change. doi.10.1007/s10113-016-1026-z.
\end{abstract}

\begin{abstract}
Livestock systems play an important role in the livelihoods of many rural communities in SubSaharan Africa whilst being responsible for an important share of human-induced greenhouse gas emissions. This study aims to evaluate the potential of adoption of climate smart agricultural practices in Sub-Saharan livestock systems, related to the improvement of feed, animal husbandry and grassland management. These practices present productivity and mitigation benefits and in some cases, may also contribute to enhance resilience. In this study we used a dataset of 1538 farm-households across nine Sub-Saharan countries. A mixed Logit model was used to assess the influence on adoption and to estimate the probability of adoption. Our results show that there seems to be a stronger influence of physical and financial capitals on adoption than the other capitals. Different types of capitals influence the uptake of different agricultural practices. Yet the probability of adoption would change across countries. The results of this study could help to refine adoption estimates calculated through global or regional modelling approaches and to inform the design of policies to better target investments in order to foster adoption.
\end{abstract}

Keywords: Adoption, Climate smart agriculture, Livestock, Capitals, Climate change, Mixed Logit, Sub-Saharan Africa 


\section{Introduction}

Livestock systems play an important role in the livelihoods of many rural communities in SubSaharan Africa (SSA). The Fifth Assessment Report of the IPCC (AR5) (Niang and Ruppel 2014) foresees with a high level of confidence that climate change will exacerbate the vulnerability of these livestock systems. There is particular concern around the impact that the increase in greenhouse gas concentration will have on exacerbating drought conditions in subtropical agriculture (Tubiello et al., 2007; Thornton et al., 2006). Total greenhouse gas emissions from the livestock supply chain represent 14.5 percent of all human-induced emissions, of which almost $7 \%$ of emissions are attributed to Sub-Saharan livestock production (Gerber et al. 2013). Nevertheless, SSA livestock production has the highest greenhouse gas emissions intensities (emissions per unit of product) due to low animal productivity and use of lowquality feeds (Herrero et al. 2013).

Numerous studies have identified a multitude of climate smart agricultural (CSA) practices with the potential to reduce greenhouse gas emissions, sustainably increase agricultural productivity and build resilience to climate change (Soussana et al. 2010; Smith et al. 2013; Herrero et al. 2010). In the sub-Saharan livestock sector, these practices can provide some mitigation benefits whilst also improving soil fertility, increase resilience to extreme weather events, alleviate feed shortages, increase income to resource poor farmers, and increase milk and meat production. Moreover, climate change policies have been developed with the aim of promoting intensification of production by improving efficiency in a sustainable manner (Herrero et al. 2010). National governments are developing numerous policies and programmes in Africa which aim at achieving sustainable development through climate change actions (e.g. AAP 2013; Beddington et al. 2012; Niang and Ruppel 2014; Dixon et al. 2003; IFAD 2013; Nzuma et al. 2010; Downing et al. 1997). AR5 highlights the need for enhancing and scaling up actions against climate change at farm and local level including principles for good practice and integrated approaches to mitigation and adaptation (IPCC 2013; Niang and Ruppel 2014). Thus evaluating farm-level adoption can be useful for designing policies to enhance capacity which both reduce greenhouse gas emissions and cope with climate change risks and impacts (Nhemachena and Hassan 2007).

In the last decade, a growing number of studies have focused on understanding the drivers of adoption of agricultural practices at the farm level, with the majority focused on the socioeconomic determinants that influence adoption. In SSA, a large body of research has been 
devoted to analyse determinants, in particular socio-demographic factors of adoption of climate change actions (e.g. Gbetibouo 2009; Deressa et al. 2009; Bryan et al. 2009; García de Jalón et al. 2015; Silvestri et al. 2012). These studies use coefficients estimated through statistical and econometric approaches to measure the effect of the socio-economic determinants. Moreover, reviews of past research (e.g. Prokopy et al. 2008; Knowler and Bradshaw 2007; Baumgart-Getz et al. 2012; García de Jalón et al. 2016) have used the statistical coefficients estimated in previous studies to identify common patterns that determine adoption across regions.

The determinants of adoption can be aligned into five types of capital which will help to identify the key causes of uptake, namely natural, social, physical, financial, and human. Many studies have assessed adoption of agricultural practices through one or more of these five types (Wheeler et al. 2013; Below et al. 2012; Gebrehiwot and van der Veen 2013; Deressa et al. 2009; Silvestri et al. 2012).

Mathematical models at global scale can provide a better understanding of how the adoption of recommended practices will spread throughout time and what policies are more likely to fail or succeed. However, adoption estimates calculated with global models may not evolve as forecasted due to these models do not consider some key biophysical or socio-economic barriers at the farm scale. Particularly the peer-effect (farmer-to-farmer effect) could play a key role not expected in the most commonly used models (García de Jalón et al. 2015). The dissemination of CSA practices can be described by the Theory of Diffusion of Innovations by Rogers (2003). This defines the different steps in the process of diffusing technologies of an innovative practice in which describe how adoption could evolve throughout time.

This study aims to assess the potential for adoption of four CSA practices at the livestock sector in SSA. In doing so this study employs an innovative approach for assessing potential for adoption of practices at the farm level in contexts where there is lack of data. Moreover, as the adoption estimates are based on farm-level data they can be used to refine estimates calculated through regional or global models at larger scales. 


\section{Data and Methods}

\subsection{Data collection}

Data used in this study were collected from the survey of the CGIAR Research program on Climate Change, Agriculture and Food Security (CCAFS), conducted between 2010 and 2011. The survey was carried out across nine different countries of SSA (Burkina Faso (BF), Ghana $(\mathrm{GH})$, Mali (ML), Niger (NE), Senegal (SN), Ethiopia (ET), Kenya (KE), Tanzania (TZ), and Uganda (UG)). In total the sample includes 1538 farm-households. Figure 1 shows the location of the eleven case studies. While the sample might not be representative of all Africa, it does represent diverse sites in terms of climate, agro-ecological zones, production systems, socioeconomic, and cultural variability. As such, it provides insights about household differences related to climate change in Africa (Twyman et al. 2014).

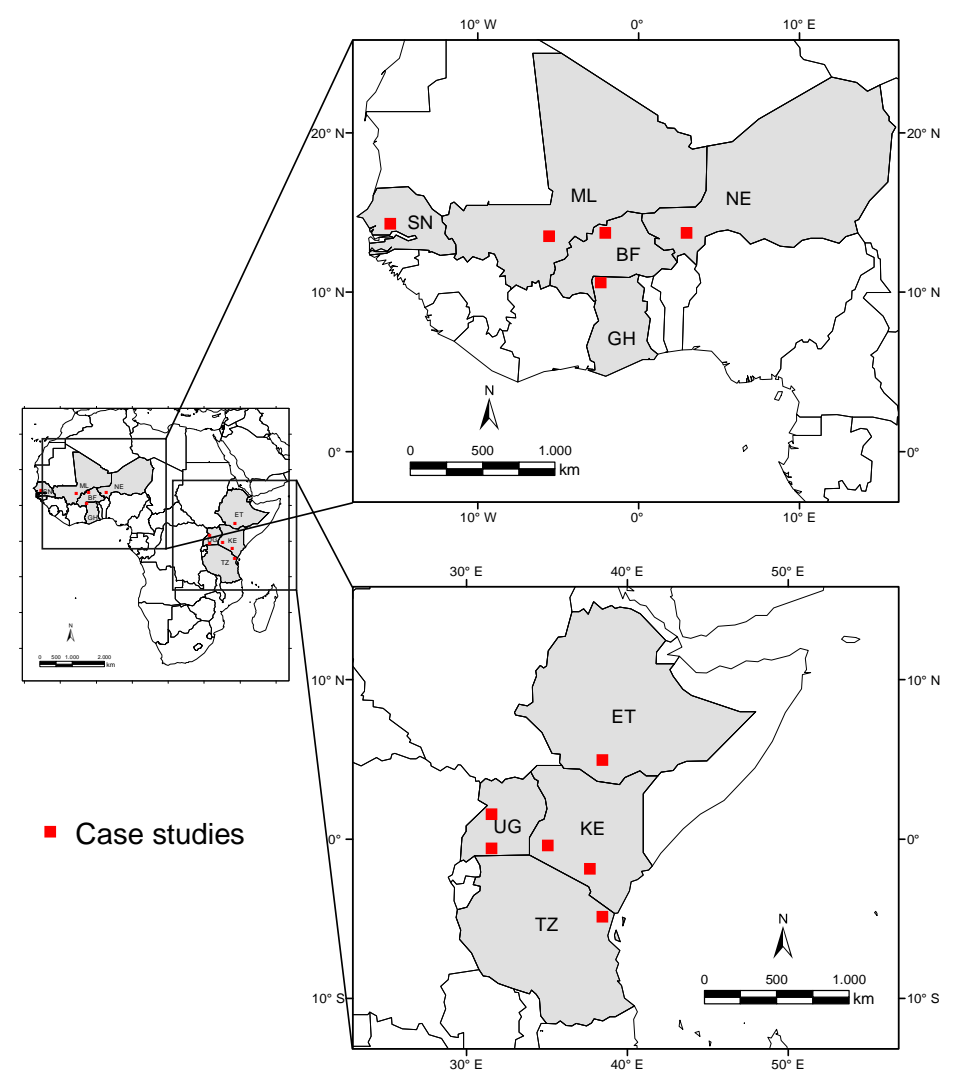

Figure 1. Location of the case studies of CCAFS survey. 


\subsection{Data analysis}

The methodological process aims to estimate potential for adoption of agricultural practices with mitigation and productivity benefits in SSA. This approach is based on observed adoption rates of proxies of CSA practices.

The following four agricultural practices for livestock production systems in SSA were identified by experts within the framework of the AnimalChange project (see ILRI (2014) for more information). These practices all concurrently contribute to achieve mitigation and adaptation to climate change.

i. Improving feed quality: Improving feed by processing crop residues and adding maize grain and maize residue to the ration. This practice positively affects the quality of the roughage which leads to enhanced overall productivity. The processing of feed residues provides a slight improvement in the feed digestibility. Furthermore due to an elevated content of starch, fermentation produces less emission of $\mathrm{CH}_{4}$ (ILRI 2014).

ii. Herd management: improving animal husbandry and health to increase fertility and decrease mortality rates. As a result of the increase in fertility rates and decrease in mortality rates less calves are needed to obtain the same level of production and therefore less $\mathrm{CH}_{4}$ emissions of the total herd are produced, while herd production is maintained.

iii. Grassland management: improving grazing management. Adequate or optimally grazed grassland management can result in higher soil $C$ than ungrazed grass due to more rapid turnover of shoot material and changes in species composition (Rees et al., 2005). However, the reduction of the grazing pressure can also lead to an increase in soil organic carbon stocks (ILRI 2014).

iv. Introducing varieties for grasslands: it refers to introducing or increasing legumes and/or Brachiaria in grasslands. Besides legumes and Brachiaria species are well adapted to future conditions with climatic change they can also lead to an increase in productivity. Legumes will also increase $\mathrm{N}$-use efficiency. This increase in productivity and $\mathrm{N}$-use efficiency offers the potential to mitigate greenhouse gas emissions (Kirwan 2007).

The data analysis can be described in the following four methodological steps:

1) Selection of proxies for the four CSA practices

The first step of the methodological process was to select agricultural practices which i) have similar drivers of adoption to our four selected practices, and for which ii) there are available data to assess the influence of their drivers on adoption(see below). The selection was based 
on the analytical soundness, measurability, and the relationship between the proxies and the CSA practices. Table 1 shows the proxies selected for each CSA practice, their mean and standard deviation, and describes the reason why each proxy was selected.

i. Improving fodder storage (e.g. hay, silage): Lack of quality fodder is a major limiting factor in improving livestock production. Improving fodder storage refers to a correct process to make hay or silage including adequate plant species with suitable moisture content.

ii. Growing fodder crops: This variable refers to correct selection of crop and grass species to make fodder.

iii. Introduced mechanized farming: It refers whether the farmer uses or not mechanized machinery for implementing any type of field operations.

iv. Planting pre-treated/improved seed: It refers whether the farmer uses seeds that have received any treatment to increase the probability of germination. This can be mechanical, water or a dry heat treatment.

v. Stall keeping introduced: It refers whether the farmer owns stalls to keep the livestock. The correct use of stalls can offer additional protection from the elements year-round such as providing shade in the hot season and act a barrier from wind and rain.

vi. Fencing introduced: It refers to the use of fencing in the grasslands. Fencing can prevent the livestock to escape and protect the livestock from predators.

vii. Introduced new breeds: It refers if the farmer has introduced new breeds of livestock to improve the productivity of the herd.

viii. Improved pastures: It refers whether the farmer has made changes in the grasslands and pastures to improve the feed quality of the livestock.

Table 1. Selected proxies of the studied climate smart agricultural practices in Sub-Saharan livestock sector. Mean values show the percentage of farmers who adopted the practice.

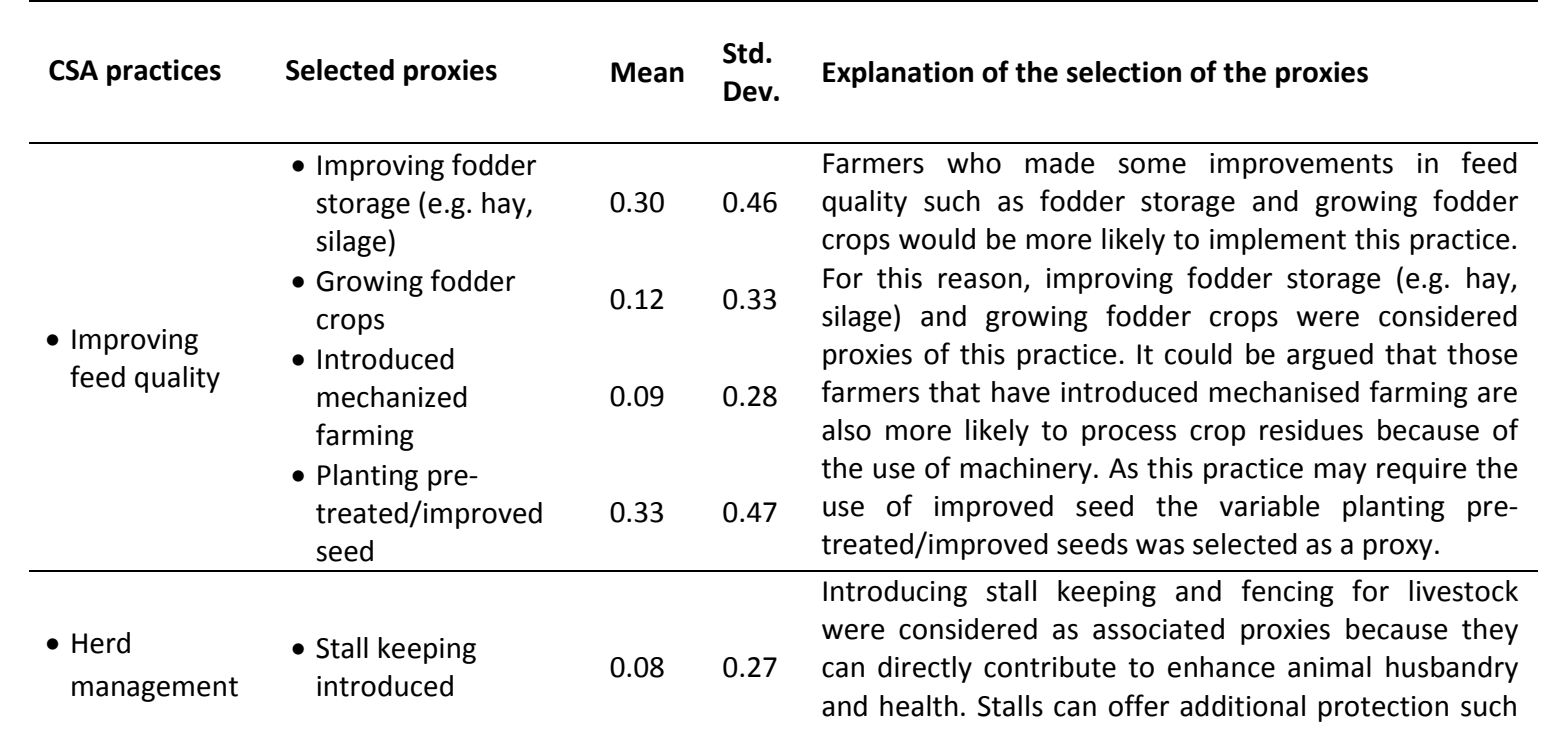




\begin{tabular}{|c|c|c|c|}
\hline $\begin{array}{l}\text { Introduced } \\
\text { mechanized } \\
\text { farming }\end{array}$ & 0.18 & 0.28 & $\begin{array}{l}\text { from wind and rain. Fencing can prevent the livestock } \\
\text { to escape and from predators which will decrease the } \\
\text { mortality rate. The use of some machinery can help } \\
\text { prevent from the spread of animal disease which also } \\
\text { can reduce the mortality rate. Therefore farmers who } \\
\text { have introduced mechanised farming are more likely } \\
\text { to adopt this measure. Introducing new breeds can } \\
\text { lead to an increase in fertility rates and a decrease in } \\
\text { mortality rates since some breeds are more tolerant to } \\
\text { certain climatic conditions and more resistant to } \\
\text { certain diseases. }\end{array}$ \\
\hline Improved pastures & 0.07 & 0.30 & $\begin{array}{l}\text { Improving pastures was selected as a proxy as it is a } \\
\text { direct indicator of improving grassland management. } \\
\text { Introducing fencing was also considered as a proxy } \\
\text { because it is part of the management of the grasslands } \\
\text { and provides several benefits. }\end{array}$ \\
\hline $\begin{array}{l}\text { - Planting pre- } \\
\text { treated/improved } \\
\text { seed }\end{array}$ & 0.33 & 0.47 & $\begin{array}{l}\text { As this practice supposes the introduction of a new } \\
\text { plant species in the grasslands farmers who were } \\
\text { already using improved seeds would be more likely to } \\
\text { adopt this practice. For this reason the variable } \\
\text { planting pre-treated/improved seed was considered as } \\
\text { a proxy. Introducing or increasing legumes and/or } \\
\text { Brachiaria in grasslands represents an improvement in } \\
\text { the grasslands management. Consequently the } \\
\text { variable improved pastures, was considered as a } \\
\text { proxy. }\end{array}$ \\
\hline
\end{tabular}

- Introducing varieties for grasslands
- Planting preated/improved management as providing shade in the hot season and act a barrier from wind and rain. Fencing can prevent the livestock prevent from the spread of animal disease which also can reduce the mortality rate. Therefore farmers who to adopt this measure. Introducing new breeds can lead to an increase in fertility rates and a decrease in mortality rates since some breeds are more tolerant to Improving pastures was selected as a proxy as it is a direct indicator of improving grassland management. and provides several benefits. already using improved seeds would be more likely to proxy.

The adoption of the selected proxies was measured as a binary variable, with 1 meaning that the practice was adopted and 0 that the practice was not adopted. In the CCAFS case studies (see Table 1) planting pre-treated or improved seeds and introducing fodder storage were more frequently adopted than the others. Around thirty percent of farmers adopted these practices in the case studies of SSA. Conversely, improving pastures, introducing stall keeping, mechanized farming, fencing and growing fodder crops were the practices least frequently adopted. Their adoption rate was around between seven and twelve percent.

\section{2) Selection of determinants of adoption}

The second step was to select drivers of adoption for the proxies of the four CSA practices. We classified the determinants of adoption according to the five types of capital: natural, physical, financial, human, and social. These capitals are stocks that have the capacity to produce flows of economically desired outputs (Goodwin 2003). Proxies of the five types of capital were selected to assess their influence on adoption. Table 2 presents the selected proxies of the five types of capital. 
Physical capital is defined as physical assets generated by applying human productive activities that are used to provide a flow of goods or services (Goodwin 2003). It represents assets such as farm inputs, infrastructure, or technology that improve crop production. The selected proxies included farm and household assets such as: livestock and land holdings, irrigation systems, electronic assets, mechanical plough and used agricultural inputs.

Social capital represents social networks and consists of trust, understanding, and cooperation between individuals and groups (Goodwin 2003). Thus, the interactions of climate change information between farmers and institutions could be considered indicators of social capital. In this study, the selection of the proxies of the five types of capital was based on the relationship between the proxies and the adoption of CSA practices. The selected proxies included membership of agricultural associations, gender of the head of the household, and various variables that attempted to capture access and ability to access climate information and extreme weather events through social networks.

Financial capital is the capital stock that facilitates economic production. The selected proxies were access to credit, having a bank account, remittances, off-farm and on-farm income.

Human capital refers to the productive capacities, knowledge, and personal attributes and values that make an individual more productive (Pindyck and Rubifeld 2013). The selected proxies included: size of the household, level of education, as well as attitudes and values towards climate change measured through farmers' decision making.

Natural capital is a stock that provides ecosystem services of the natural world which yields a valuable flow of goods and services into the future (Costanza and Daily 1992). In terms of agriculture, natural capital represents climate and soil characteristics which predetermine the suitability for agriculture. This kind of biophysical data were not included in the survey and therefore their proxies were derived from other databases including: annual precipitation, length of growing period and the difference between precipitation and potential evapotranspiration. The proxies for annual precipitation and the difference between precipitation and evaporation were obtained from WorldClim database (www.worldclim.org/). The selected values were the average between 1950 and 2000. The indicators of length of growing period were obtained from FAO (www.fao.org/geonetwork/) over the time period 1963 to 2000.

Table 2. Selected proxies of the five kinds of capital used to assess the adoption of agricultural practices in Sub-Saharan Africa 


\begin{tabular}{|c|c|c|c|c|c|c|}
\hline Capital & Proxies of capital & Units and Scale & Mean & $\begin{array}{l}\text { Std. } \\
\text { Dev. }\end{array}$ & Min & Max \\
\hline \multirow{7}{*}{ Physical } & Owned acreage & Hectares & 7.09 & 15.50 & 0 & 300 \\
\hline & Large owned livestock & $1=$ Yes, $0=$ Otherwise & 0.56 & 0.50 & 0 & 1 \\
\hline & Having mechanical plough & $1=$ Yes, $0=$ Otherwise & 0.23 & 0.42 & 0 & 1 \\
\hline & $\begin{array}{l}\text { Having electronic assets in the household } \\
\text { (e.g. TV, radio, phone, Internet, computer) }\end{array}$ & $1=$ Yes, $0=$ Otherwise & 0.29 & 0.17 & 0 & 1 \\
\hline & Irrigation systems & $1=$ Yes, $0=$ Otherwise & 0.06 & 0.12 & 0 & 0.67 \\
\hline & $\begin{array}{l}\text { Household structures (e.g. crop storage } \\
\text { facility, concrete and bricks, tap water, etc.) }\end{array}$ & $1=$ Yes, $0=$ Otherwise & 0.18 & 0.18 & 0 & 1 \\
\hline & Separate housing for farm animals & $1=$ Yes, $0=$ Otherwise & 0.41 & 0.49 & 0 & 1 \\
\hline \multirow{7}{*}{ Social } & Membership in an agricultural group & $1=$ Yes, $0=$ Otherwise & 0.32 & 0.47 & 0 & 1 \\
\hline & $\begin{array}{l}\text { Access to information about climate } \\
\text { extreme events (drought, floods, etc.) }\end{array}$ & $1=$ Yes, $0=$ Otherwise & 0.58 & 0.50 & 0 & 3 \\
\hline & Gender of the household headed & $\begin{array}{l}1=\text { Female headed, } 0= \\
\text { Otherwise }\end{array}$ & 0.16 & 0.37 & 0 & 1 \\
\hline & Ability to access weather forecast $2-3$ days & $1=$ Yes, $0=$ Otherwise & 0.16 & 0.37 & 0 & 1 \\
\hline & $\begin{array}{l}\text { Ability to access information about rain } \\
\text { forecast }\end{array}$ & $1=$ Yes, $0=$ Otherwise & 0.41 & 0.49 & 0 & 1 \\
\hline & $\begin{array}{l}\text { Ability to access weather forecast } 2-3 \\
\text { months }\end{array}$ & $1=$ Yes, $0=$ Otherwise & 0.23 & 0.42 & 0 & 1 \\
\hline & $\begin{array}{l}\text { Ability to access information about climate } \\
\text { extreme events (drought, floods, etc.) }\end{array}$ & $1=$ Yes, $0=$ Otherwise & 0.34 & 0.47 & 0 & 1 \\
\hline \multirow{10}{*}{ Financial } & Having a bank account & $1=$ Yes, $0=$ Otherwise & 0.09 & 0.29 & 0 & 1 \\
\hline & Access to credit/loan & $1=$ Yes, $0=$ Otherwise & 0.13 & 0.34 & 0 & 1 \\
\hline & Receiving remittances & $1=$ Yes, $0=$ Otherwise & 0.32 & 0.47 & 0 & 1 \\
\hline & Receiving off-farm paid employment & $1=$ Yes, $0=$ Otherwise & 0.19 & 0.39 & 0 & 1 \\
\hline & Receiving cash from fruits & $1=$ Yes, $0=$ Otherwise & 0.26 & 0.44 & 0 & 1 \\
\hline & Receiving cash from vegetables & $1=$ Yes, $0=$ Otherwise & 0.24 & 0.43 & 0 & 1 \\
\hline & Receiving cash from wood & $1=$ Yes, $0=$ Otherwise & 0.08 & 0.28 & 0 & 1 \\
\hline & Receiving cash from large livestock & $1=$ Yes, $0=$ Otherwise & 0.27 & 0.45 & 0 & 1 \\
\hline & Receiving cash from small livestock & $1=$ Yes, $0=$ Otherwise & 0.64 & 0.48 & 0 & 1 \\
\hline & Receiving cash from livestock products & $1=$ Yes, $0=$ Otherwise & 0.33 & 0.47 & 0 & 1 \\
\hline \multirow{5}{*}{ Human } & Education & $\begin{array}{l}0=\text { No formal } \\
\text { education, } 1=\text { Primary, } \\
2=\text { Secondary, } 3=\text { Post } \\
\text { Secondary }\end{array}$ & 1.23 & 0.79 & 0 & 3 \\
\hline & Household size (number of people) & Number of people & 9.12 & 7.70 & 1 & 85 \\
\hline & Changes adopted because less rainfall & $1=$ Yes, $0=$ Otherwise & 0.61 & 0.49 & 0 & 1 \\
\hline & Changes adopted because more droughts & $1=$ Yes, $0=$ Otherwise & 0.53 & 0.50 & 0 & 1 \\
\hline & Changes adopted because later start of rains & $1=$ Yes, $0=$ Otherwise & 0.54 & 0.50 & 0 & 1 \\
\hline \multirow{3}{*}{ Natural } & Annual precipiation & Millimeters & 851.7 & 315.3 & 438 & 1384 \\
\hline & $\begin{array}{l}\text { Difference between annual precipitation } \\
\text { and evapotranspiration }\end{array}$ & Millimeters & -903.3 & 494.2 & -1962 & -216 \\
\hline & Length of growing period & Days & 113.6 & 56.9 & 50 & 210 \\
\hline
\end{tabular}

\section{3) Assessing the influence of the five types of capital on adoption}


The influence of the five types of capital on the adoption of the selected proxies of practices was assessed by a generalised linear mixed model (GLMM) through the observed data from the CCAFS survey. In the logistic regressions of the GLMM, the adoption of the practices is treated as a binary dependent variable (with the value of 1 indicating adoption) and the five types of capital are used as predictors. In this way, a random intercept Logit model was developed, having random effects for each village where the survey had been implemented (80 villages across the nine countries).

Eq. (4) describes the random intercept Logit model in terms of a latent linear response, where only $y_{i j}=I\left(y_{i j}^{*}>0\right)$ is observed for the latent

$$
y_{i j}^{*}=X_{i j} \beta+Z_{i j} U_{j}+\varepsilon_{i j}
$$

Where $y_{\mathrm{ij}}^{*}$ indicated the probability of success, which was the probability of adopting a determined practice conditioned to the independent variables for each farm. The dependent variables were dummy variables taking the value of 1 if farm $i$ adopted a determined practice and 0 otherwise. $l$ is the identity matrix in which all elements of the matrix are zero except the elements in the first diagonal that are equal to one. $X_{i j}$ are the covariates for the fixed effects (i.e. five capitals) of farm-household $i$ in village $j$, with regression coefficients (fixed effects) $\beta$. $Z_{i j}$ are the covariates corresponding to the random effects and can be used to represent both random intercepts and random coefficients. As our case is a random intercept model, $Z_{i j}$ equals the scalar $1 . U_{j}$ represents the error term for the random effects of the 80 villages which are estimated as variance components. $\varepsilon_{i j}$ are the errors distributed as logistic with mean 0 and variance $\pi^{2} / 3$ and are independent of $U_{j}$.

Defining $\pi_{i j}=\operatorname{Prob}\left(\right.$ adoption $\left._{i j}=1\right)$, equation (5) shows the final random intercept Logit model,

$\operatorname{logit}\left(\pi_{i j}\right)=\beta_{0}+\beta_{1}$ Human $_{i j}+\beta_{2}$ Natural $_{i j}+\beta_{3}$ Physical $_{i j}+\beta_{4}$ Social $_{i j}+\beta_{5}$ Financial $_{i j}+U_{j}$

for $j=1, \ldots, 80$, with $i=1, \ldots, n_{j}$ farm-households in village $j$.

\section{4) Evaluating potential for adoption of the agricultural practices}

The last step was to evaluate the potential for adoption of the four CSA practices. The likelihood of adoption was derived from the coefficients of the proxies estimated through the mixed Logit model. The probability of adoption of each proxy was calculated by substituting 
the betas $\left(\beta_{0}-\beta_{5}\right)$ in Equation 5 by the estimated coefficients in the logistic regressions. Finally the potential for adoption of each CSA practice was calculated as the average of the estimated probabilities of their respective proxies.

\section{Results}

\subsection{Influence of the five types of capital on adoption}

Table 3 presents the estimated coefficients of the mixed logistic regressions. Overall, all types of capitals, except natural capital, have a positive and significant effect on the uptake of the practices. This confirms the findings of previous studies that highlight the importance of all types of capital on adoption of innovative or recommended agricultural practices (e.g. Wheeler et al. 2013; Thornton et al. 2006; Nelson et al. 2005; Below et al. 2012). The coefficients of the logistic regressions show that physical and financial capitals seem to have stronger influence on adoption than the other capitals. The high correlation between adoption and physical and financial capitals does not necessarily mean that physical and financial capitals are the most powerful drivers of adoption. The adoption of the practices could also affect the capitals of the farm. Yet, different types of capitals can influence the uptake of different practices. For example improved pastures, can be influenced by physical and financial capital, while planting pre-treated/improved seeds can be determined by human, natural, physical, social and financial capital.

Natural capital is the only capital that presents a significantly negative effect on adoption. In this study, the proxies used to form natural capital mainly indicated the aridity and humidity of the climate in the location of the case studies (i.e. annual rainfall, potential evapotranspiration, and length of growing period). Thus a positive coefficient of natural capital indicates that farmhouseholds located in a humid climate are more likely to adopt. In the practice 'introducing fodder storage', natural capital negatively correlates with adoption $(6=-2.52, p<.001)$, this may indicate that households in arid areas store more fodder as result of the high variability in fodder provision due to the arid climate.

Table 3. Estimated coefficients of mixed logistic regressions assessing adoption of the agricultural practices. 


\begin{tabular}{|c|c|c|c|c|c|c|c|c|}
\hline & 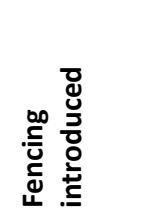 & 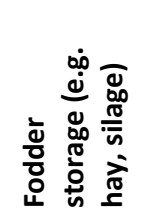 & 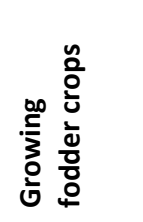 & 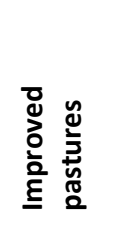 & 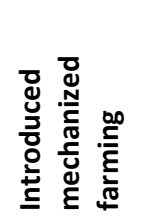 & 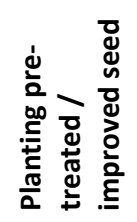 & 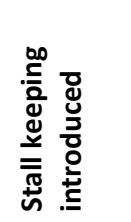 & 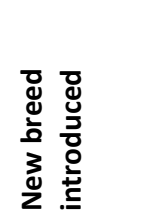 \\
\hline Human & $1.00 * * *$ & $1.01 * * *$ & $0.61 * *$ & 0.20 & $1.5^{* * *}$ & $0.99 * * *$ & 0.25 & $0.57^{* * *}$ \\
\hline Natural & -0.56 & $-2.52 * * *$ & $0.97 * *$ & -0.31 & -0.74 & $1.64 * * *$ & $2.6 * * *$ & 0.44 \\
\hline Physical & $0.94 * * *$ & $1.32 * * *$ & $1.25^{* * *}$ & $0.79 * * *$ & $0.85^{* * *}$ & $1.18^{* * *}$ & $0.99 * * *$ & $0.85^{* * *}$ \\
\hline Social & $0.40 *$ & 0.28 & $0.52^{* *}$ & 0.09 & -0.36 & $0.41^{* *}$ & $0.9 * * *$ & 0.23 \\
\hline Financial & $1.01 * * *$ & $0.72^{* *}$ & $1.51 * * *$ & $0.84 * *$ & $1.6^{* * *}$ & $0.96 * * *$ & $1.37^{* * *}$ & $1.58 * * *$ \\
\hline Constant & $-3.75 * * *$ & $-1.06 * * *$ & $-4.22 * * *$ & $-3.48 * * *$ & $-5.46 * * *$ & $-2.92 * * *$ & $-5.81 * * *$ & $-2.79 * * *$ \\
\hline \multicolumn{9}{|c|}{ Random-effects Parameters } \\
\hline Estimate & 1.47 & 1.19 & 1.64 & 1.21 & 2.53 & 1.58 & 1.39 & 1.17 \\
\hline Std. Error & 0.22 & 0.15 & 0.23 & 0.21 & 0.41 & 0.18 & 0.26 & 0.15 \\
\hline Number of obs. & 1538 & 1538 & 1538 & 1538 & 1538 & 1538 & 1538 & 1538 \\
\hline $\begin{array}{l}\text { Number of } \\
\text { groups }\end{array}$ & 80 & 80 & 80 & 80 & 80 & 80 & 80 & 80 \\
\hline Log likelihood & -401.7 & -703.8 & -446.4 & -340 & -289.5 & -719.3 & -303.2 & -623.78 \\
\hline Wald chi ${ }^{2}(5)$ & $46.8^{* * *}$ & $123.1^{* * *}$ & $72.2^{* * *}$ & $18.9 * * *$ & $40.1^{* * *}$ & $89.8^{* * *}$ & $72.7^{* * *}$ & $69.4^{* * *}$ \\
\hline Chibar $^{2}(01)$ & $100.8^{* * *}$ & $120.7^{* * *}$ & $151.8^{* * *}$ & $44.3^{* * *}$ & $202 * * *$ & $256 * * *$ & $59.3 * * *$ & $121.42^{* * *}$ \\
\hline
\end{tabular}

\subsection{Assessing potential for adoption}

The last step was to evaluate the potential for adoption of each CSA practice for targeting livestock. Following Equation 5, the estimated coefficients of the mixed logistic regressions were used to calculate the likelihood of adoption for each proxy. Subsequently the potential for adoption of the four practices was calculated as the average of the probability of the proxies.

Figure 2 shows the distribution of the predicted probabilities of adoption to the four CSA practices. Considering the median values, the estimated probability of adoption of the four practices range from approximately $3 \%$ to $16 \%$. The practices improving feed quality and introducing plant varieties for grasslands present the highest likelihood of adoption. Planting pre-treated/improved seeds was selected as a proxy of both practices. The CCAFS survey shows that planting pre-treated/improved seeds has been a practice frequently adopted among Sub-Saharan farmers, which explains the relatively high probability of introducing plant varieties for grasslands and improving feed quality. The elevated rate of adoption in comparison with the others could be explained due to their low cost of investment and the economic and soil quality benefits obtained in the short term. Moreover, the private sector has an evident interest in promoting this practice and seed dealers are often one of the 
sources that farmers trust the most (Lemos et al. 2014). Herd management and grassland management have a very low probability of adoption. These practices present elevated costs for the household and this may explain their low level of adoption (median values around $3 \%$ ).

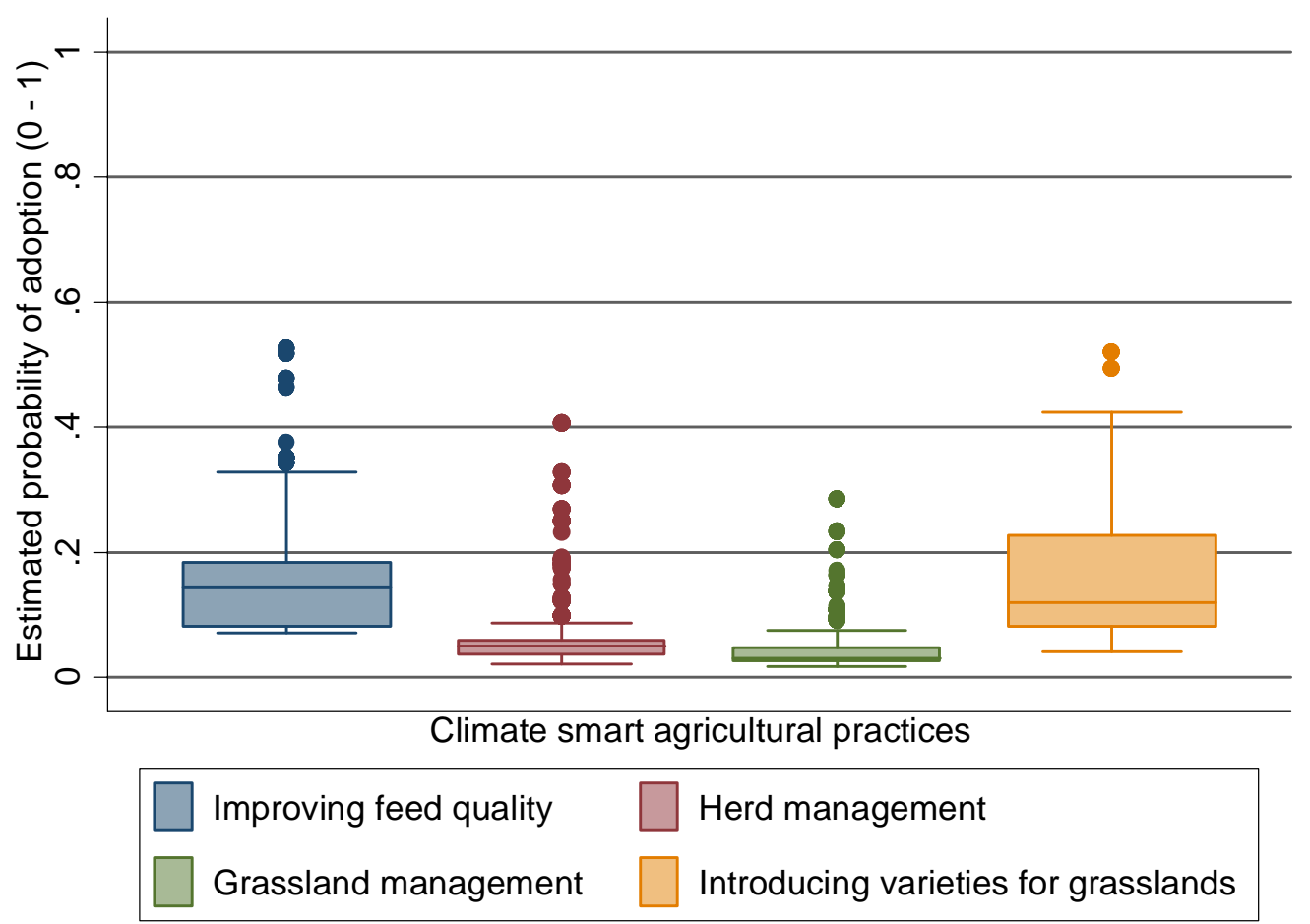

Figure 2. Estimated probability of adoption of the climate smart agricultural practices for the livestock systems in the case studies of CCAFS survey. Middle horizontal lines within each box indicate the median, boxes extend from the 25th to 75th percentile and vertical lines extend from 5th to 95th percentile of estimations.

Figure 3 shows the estimated probability of adoption of the four CSA practices by the case study developed in each country. The analysis per country does not aim to represent the whole country rather the study sites and the differences across the study sites. The results seem to indicate that the highest probability of adoption can be found in Kenya, Tanzania, Burkina Faso and Ghana. On the contrary, Ethiopia, Mali and Niger present the lowest likelihood of adoption of the four practices. It is worth highlighting that these three countries also present the lowest Gross Domestic Product (GDP) per capita (Ethiopia had \$1,000 GDP per capita in 2010, Mali \$1,200 GDP per capita and Niger $\$ 700$ GDP per capita). This finding seems to indicate that poorer regions will probably have a lower adoption rate. 
The probability of adoption follow similar dynamics across the different countries, with a substantially higher potential for Improving feed quality and Introducing varieties for grassland. This finding suggests that adoption is also 'practice-related' and that some practices have more likelihood of uptake than others across the different countries. Improving feed quality seems to have a higher likelihood of adoption in Kenya, Ghana, Mali, and Burkina Faso. Herd management and Grassland management present values close to zero in most study sites. Although it is still very close to zero, Burkina Faso has the highest potential for adoption for both practices. Introducing or increasing the use of legumes and Brachiaria (Introducing varieties for grassland) has the highest likelihood of adoption in Ghana, Kenya, Tanzania and Uganda. The study sites in these countries present climates with a rainfall distribution more uniform, and consequently more suitable for agriculture, than the other study sites. This finding could suggest that regions less suitable for agriculture, such as arid regions, are less likely to adopt legumes and Brachiaria. These results could be explained by either biophysical factors, such as for example the type of natural habitat required for the growth of Brachiaria and legumes (Miles et al. 1996), the type of climate which would be more or less suitable for agriculture, as well as economic and technological capacity to adopt farm-management changes (Ayele and Wield 2005). It is noteworthy that the estimated probability of adoption only determines the potential for adoption and does not determine actual adoption. Actual adoption is ultimately driven by specific characteristics (socio-economic and agro-climatic) and farm-decisions made at the farm level. 


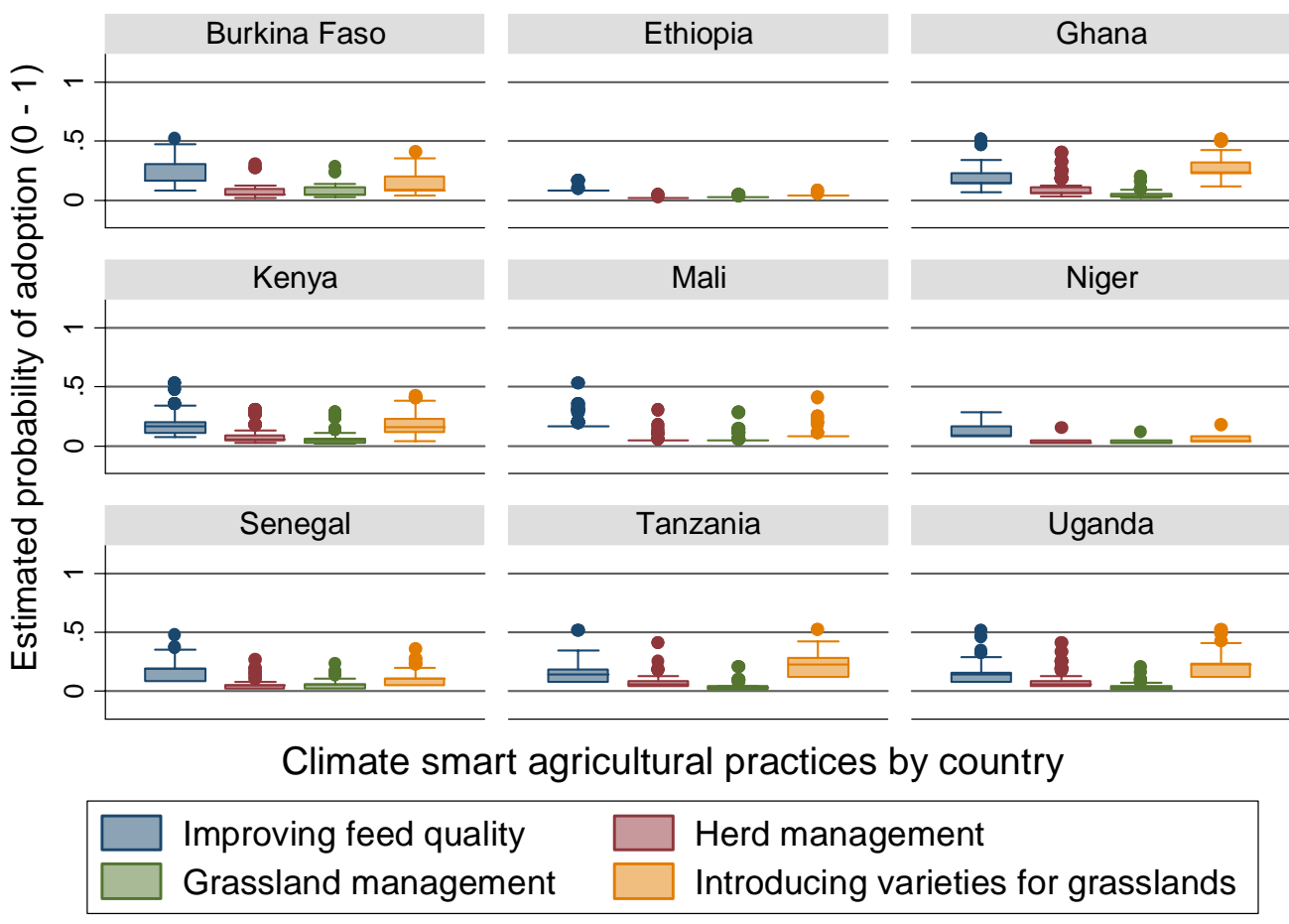

Figure 3. Estimated probability of adoption of the climate smart agricultural practices for the livestock systems in the case studies of CCAFS survey. Middle horizontal lines within each box indicate the median, boxes extend from the 25th to 75th percentile and vertical lines extend from 5th to 95th percentile of estimations.

\section{Discussions and conclusions}

This study presents an approach to evaluating smallholders' uptake of agricultural practices with both mitigation and productivity benefits in Sub-Saharan livestock systems. This represents an important tool when predicting adoption of a practice when there are no data available. It is worth highlighting two limitations of this study for taking forward. Firstly, to derive the uptake of the four selected practices, we had to select agricultural practices where adoption is driven by similar determinants. Consequently, this needs to be based on proxies or indicators. Secondly, the potential for adoption of the four practices was calculated as the average of the probability of the proxies, assuming the same weight for all proxies. Further research would include assigning the weights of the proxies. This could be done by using a survey with main experts and stakeholders. The Analytical Hierarchical Process technique by pairwise comparisons would be very suitable to assign weights. 
Results indicate that overall financial and physical capitals are the most powerful predictors on the adoption of the selected CSA practices. This approach only considered that adoption is influenced by the five types of capitals and did not consider that capitals could also be affected by adoption. According to the logit model results, the policy implications could be to invest in overcoming financial and physical constraints such as access to market and credit accessibility and enhancing farm-household assets such as infrastructure, quality inputs for crop production, and household asset such as domestic access to water, electricity and separate housing for farm animals in order to enhance the uptake of the selected practices. Nevertheless, as the effect of adoption on capitals will not be the same on each type of capital it is possible that the high correlation between adoption and physical and financial capitals does not necessarily mean that they are the most powerful predictors.

All capitals except natural capital have a clear positive effect on adoption. Hence this seems to indicate that adoption can be fostered in a number of ways, i.e. by intervening to enhance indicators of the different types of capital. Policy makers would be interested in the most effective ways to improve adoption at minimal costs. For instance, although social capital was not the most powerful one, investing in social capital indicators, such as extension services or support for agricultural associations could contribute to overcoming social barriers for the adoption of recommended practices. Social barriers have been widely described in the literature to be an important cause of failure of adopting recommended practices that do not require a substantial financial investment (Nielsen and Reenberg 2010; Adger et al. 2009; García de Jalón et al. 2015). In the literature, numerous studies have highlighted the relevant role that social capital and its indicators play on the uptake of recommended practices (Abebe et al. 2013, Below et al. 2012; Baumgart-Getz et al. 2012).

Natural capital had a negative effect on fodder storage, fencing introduced, improved pastures, and introduced mechanised farming. However, only in fodder storage was the effect statistically significant. The negative and significant effect on fodder storage suggests, rather intuitively, that farmers in drier regions are more likely to introduce fodder storage. Moreover, in growing fodder crops, planting pre-treated/improved seed and stall keeping the relationship between natural capital and adoption was positive, which indicates that farmers in wetter regions are more likely to adopt. Increasing volatility, warming and aridity in the future can affect indicators of natural capital which might influence the adoption of practices distinctly.

The predicted probabilities show that the likelihood of adoption can notably vary among farmhouseholds in SSA, which is reasonable, considering we assessed farm-level adoption with a 
range of natural conditions and socio-economic contexts. The results show that almost a hundred percent of the households presented a likelihood of adoption lower than fifty percent. This indicates that it is very likely that a large number of farm-households in SSA might not adopt any of the CSA agricultural practices in the coming years. This means that unless effective programmes and policies are developed farmers are most likely non-adopters. Thus policy makers need to develop effective programs and policies to achieve adoption of CSA practices while agricultural technical advisors and extension services can help to overcome barriers of lack of knowledge.

The adoption of these practices may not always guarantee achieving productivity and mitigation objectives due to regional characteristics such as climate and soil and an adequate implementation of the practice. Furthermore, the adoption of these practices may entail some risk implications for farmers. For instance, the inadequate implementation of the practice due to lack of knowledge can not only hinder the achievement of climate smart objectives but also lead to a decrease in productivity and net farm-income. As these risk implications can lead farmers to refuse to adopt innovative practices, demonstration sites and extension services can play a key role in fostering adoption. Herrero et al. (2010) claimed that policies targeting adoption of climate change actions among smallholder farmers should invest in intensive production by carefully managing inputs of fertilizer, water, and feed to minimize waste and environmental impact, supported by improved access to markets and technologies. These represent indicators of physical and financial capital. Accordingly, our results align with those of Herrero et al. (2010) since the logistic regressions suggested that farmers with higher physical and financial capital are more likely to adopt recommended practices. Thus policies aiming at improving indicators of physical and financial capitals could lead to increase adoption rates of recommended practices.

Introducing plant varieties for grasslands seems to be the CSA practice most likely to be implemented in the case studies of Eastern Africa. Sowing legumes and Brachiaria, besides offering the potential to reduce greenhouse gas emissions due to a reduction of nitrogen use, can provide multiple benefits for the farm such as increasing productivity, improving soil fertility and structuring and breaking weeds, disease and insect biological cycles if they are adequately implemented (Kirwan 2007; ILRI 2014). In the case studies of Western Africa, improving feed quality and introducing plant varieties for grasslands are the practices with higher potential for adoption. The estimated potential for adoption can also be used as a policy recommendation of what practices should be fostered, as the approach suggests how likely farmers will adopt. 
The method developed in this study can be used in combination with other approaches that estimate adoption rates. For instance, in order to estimate adoption at large scales, marginal abatement cost curves are used in optimisation models that often maximise net farm-income and are subject to certain constraints such as land and water availability, food demand and greenhouse gas emissions. Thus in order to maximise farm-income optimisation models can suggest full adoption of a practice in a region. This can be due to the fact that the economic profitability of the practice in theory is higher than other practices. However, there are numerous barriers such as lack of knowledge, access to markets or biophysical constraints at the plot level that ultimately determine adoption. Accordingly, by highlighting the heterogeneity in adoption our approach could be used as a 'friction' coefficient in order to refine estimates made by models at large scales. This would be the estimated potential for adoption which would be calculated according to the levels of different capitals in the area of study.

This study has evaluated the potential for adoption of four CSA practices across rural communities in sub-Saharan livestock systems. This approach is useful for assessing the potential for adoption of agricultural practices that are not currently being implemented or, because of lack of data adoption, cannot be estimated directly through other approaches. This requires survey data of selected proxies for the practices and calculates probabilities of adoption based on these proxies. Thus the results can represent a first step to more accurately estimate potential for mitigation of greenhouse gas emissions in Sub-Saharan livestock systems.

\section{Acknowledgements}

This research was funded by the European Commission Animal Change project (contract no. KBBE-266018) (http://www.animalchange.eu/) and the CGIAR research program on Climate Change Agriculture and Food Security (CCAFS). 


\section{References}

Abebe GK, Bijmana J, Pascucci S, Omta O (2013) Adoption of improved potato varieties in Ethiopia: The role of agricultural knowledge and innovation system and smallholder farmers' quality assessment. Agricultural Systems 122: 22-32

Adger WN, Dessai S, Goulden M, Hulme M, Lorenzoni I, Nelson DR, Naess LO, Wolf J, Wreford A (2009) Are there social limits to adaptation to climate change? Climatic Change 93: $335-354$

Africa Adaptation Programme (AAP) (2013) AAP Terminal Report. Available at: http://www.undp-aap.org/resources/publications/aap-terminal-report. Accessed October 2014

Ayele S, Wield D (2005) Science and Technology capacity building and partnership in African agriculture: perspectives on Mali and Egypt. Journal of International Development 17: 631-646

Baumgart-Getz A, Prokopy LS, Floress K (2012) Why farmers adopt best management practice in the United States: A meta-analysis of the adoption literature. Journal of Environmental Management 96: 17-25

Beddington J, Asaduzzaman M, Clark M, Fernández A, Guillou M, Jahn M, Erda L, Mamo T, Van Bo N, Nobre CA, Scholes R, Sharma R, Wakhungu J (2012) Achieving food security in the face of climate change: Final report from the Commission on Sustainable Agriculture and Climate Change. CGIAR Research Program on Climate Change, Agriculture and Food Security (CCAFS). Copenhagen, Denmark. Available at: www.ccafs.cgiar.org/commission. Accessed July 2014

Below TB, Mutabazi KD, Kirschke D, Franke C, Sieber S, Sieber R, Tscherning K (2012) Can farmers' adaptation to climate change be explained by socio-economic household-level variables? Global Environmental Change 22: 223-235

Bryan E, Deressa TT, Gbetibouo GA, Ringler C (2009) Adaptation to climate change in Ethiopia and South Africa: options and constraints. Environmental Science \& Policy 12(4): 413426 
Costanza R, Daly HE (1992) Natural Capital and Sustainable Development. Conservation Biology $6(1): 37-46$

Deressa TT, Hassan RM, Ringler C, Alemu T, Yesuf M (2009) Determinants of farmers' choice of adaptation methods to climate change in the Nile Basin of Ethiopia. Global Environmental Change 19: 248-255

Dixon RK, Smith J, Guill S (2003) Life on the edge: vulnerability and adaptation of African ecosystems to global climate change. Mitigation and Adaptation Strategies for Global Change 8: 93-113

Downing TE, Ringius L, Hulme M, Waughray D (1997) Adapting to climate change in Africa. Mitigation and Adaptation Strategies for Global Change 2: 19-44

García de Jalón S, Iglesias A, Barnes AP (2016) Drivers of farm-level adaptation to climate change in Africa: an evaluation by a composite index of potential adoption. Mitig Adapt Strateg Glob Change 21: 779-798

García de Jalón S, Silvestri S, Granados A, Iglesias A (2015) Behavioural barriers in response to climate change in agricultural communities: an example from Kenya. Reg Environ Change 15 (5): 851-865

Gbetibouo GA (2009) Understanding farmers' perceptions and adaptations to climate change and variability: the case of the Limpopo Basin, South Africa. IFPRI Discussion Paper 00849. International Food Policy Research Institute (IFPRI), Washington, DC, 52 pp

Gebrehiwot T, van der Veen A (2013) Farm Level Adaptation to Climate Change: The Case of Farmer's in the Ethiopian Highlands. Journal of Environmental Management 52: 29-44

Gerber PJ, Steinfeld H, Henderson B, Mottet A, Opio C, Dijkman J, Falcucci A, Tempio G (2013) Tackling climate change through livestock: a global assessment of emissions and mitigation opportunities. Food and Agriculture Organization of the United Nations, Rome. Available at: http://www.fao.org/docrep/018/i3437e/i3437e.pdf. Accessed April 2015

Goodwin NR (2003) Five Kinds of Capital: Useful Concepts for Sustainable Development. G-DAE Working Paper No. 03-07 
Herrero M, Havlík P, Valin H, Notenbaert A, Rufino MC, Thornton PK, Blümmel M, Weiss F, Grace D, Obersteiner M (2013) Biomass use, production, feed efficiencies, and greenhouse gas emissions from global livestock systems. PNAS 110 (52): 20888-20893

Herrero M, Thornton PK, Notenbaert AM, Wood S, Msangi S, Freeman HA, Bossio D, Dixon J, Peters M, van de Steeg J, Lynam J, Parthasarathy Rao P, Macmillan S, Gerard B, McDermott J, Seré C, Rosegrant M (2010) Smart Investments in Sustainable Food Production: Revisiting Mixed Crop-Livestock Systems. Science 327: 822-825

IFAD (2008) IFAD's response to climate change through support to adaptation and related actions. Strengthening IFAD's capacity to mainstream climate change adaptation in its operations. Comprehensive report: Final version. Available at: http://www.ifad.org/climate/resources/adaptation.pdf. Accessed September 2014

ILRI (2014) Potential impacts of the mitigation and adaptation options in terms of GHG emissions. Deliverable 12.3 of AnimalChange Project. Grant Agreement Number FP7266018

IPCC (2013) Summary for Policymakers. In: Climate Change 2013: The Physical Science Basis. Contribution of Working Group I to the Fifth Assessment Report of the Intergovernmental Panel on Climate Change [Stocker, T.F., D. Qin, G.-K. Plattner, M. Tignor, S.K. Allen, J. Boschung, A. Nauels, Y. Xia, V. Bex and P.M. Midgley (eds.)]. Cambridge University Press, Cambridge, United Kingdom and New York, NY, USA

Kirwan L, Lüscher A, Sebastià MT, Finn JA, Collins RP, Porqueddu C, Helgadottir A, Baadshaug $\mathrm{OH}$, Brophy C, Coran C, Dalmannsdóttir S, Delgado I, Elgersma A, Fothergill M, FrankowLindberg BE, Golinski P, Grieu P, Gustavsson AM, Höglind M, Huguenin-Elie O, Iliadis C, Jørgensen M, Kadziuliene Z, Karyotis T, Lunnan T, Malengier M, Maltoni S, Meyer V, Nyfeler D, Nykanen-Kurki P, Parente J, Smit HJ, Thumm U, Connolly J (2007) Evenness drives consistent diversity effects in intensive grassland systems across 28 European sites. Journal of Ecology 95: 530-539

Knowler D, Bradshaw B (2007) Farmers' adoption of conservation agriculture: A review and synthesis of recent research. Food Policy 32: 25-48 
Lemos MC, Lo YJ, Kirchhoff C, Haigh T (2014) Crop advisors as climate information brokers: Building the capacity of US farmers to adapt to climate change. Climate Risk Management 4-5: 32-42

Miles JW, Maass BL, Valle CB (1996) Brachiaria: Biology, Agronomy, and Improvement. CIAT, 288pp. Available at: http://ciatlibrary.ciat.cgiar.org:8080/jspui/bitstream/123456789/944/1/Brachiaria.pdf. Accessed April 2015

Nelson R, Kokic P, Elliston L, King J (2005) Structural Adjustment: a vulnerability index for Australian broadacre agriculture. Australian Commodities 12: 171-179

Nielsen $\rfloor \varnothing$, Reenberg A (2010) Cultural barriers to climate change adaptation: A case study from Northern Burkina Faso. Global Environmental Change 20: 142-152

Nhemachena C, Hassan R (2007) Micro-level analysis of farmers' adaptation to climate change in Southern Africa. IFPRI Discussion Paper No. 00714. International Food Policy Research Institute, Washington, DC. Available at: http://www.ifpri.org/sites/default/files/publications/ifpridp00714.pdf. Accessed January 2014

Niang I, Ruppel OC (2014) Chapter 22. Africa. In Field et al. (eds.) Climate Change 2014: Impacts, Adaptation, and Vulnerability. Part A: Global and Sectoral Aspects. Contribution of Working Group II to the Fifth Assessment Report of the Intergovernmental Panel on Climate Change. Cambridge University Press, Cambridge, United Kingdom and New York, NY, USA

Nielsen J $\varnothing$, Reenberg A (2010) Cultural barriers to climate change adaptation: A case study from Northern Burkina Faso. Global Environmental Change 20: 142-152

Nzuma JM, Waithaka M, Mulwa RM, Kyotalimye M, Nelson G (2010) Strategies for Adapting to Climate Change in Rural Sub-Saharan Africa. A Review of Data Sources, Poverty Reduction Strategy Programs (PRSPs) and National Adaptation Plans for Agriculture (NAPAs) in ASARECA Member Countries. IFPRI Discussion Paper 01013. Environment and Production Technology Division. Available http://www.ifpri.org/publications/results/taxonomy\%3A468. Accessed November 2014

Pindyck RS, Rubifeld DL (2013) Microeconomics, 8th Ed. Pearson Education, Inc, New Jersey 
Prokopy LS, Floress K, Klotthor-Weinkauf D, Baumgart-Getz A (2008) Determinants of agricultural best management practice adoption: Evidence from the literature. Journal of Soil and Water Conservation 63(5): 300-311

Rees RM, Bingham IJ, Baddeley JA, Watson CA (2005) The role of plants and land management in sequestering soil carbon in temperate arable and grassland ecosystems. Geoderma 128 (1-2): 130-154

Rogers E (2003). Diffusion of Innovations, 5th Edition. Simon and Schuster. ISBN 978-0-74325823-4, p. 150

Silvestri S, Bryan E, Ringler C, Herrero M, Okoba B (2012) Climate change perception and adaptation of agro-pastoral communities in Kenya. Reg Environ Change 12: 791-802

Smith P, Haberl H, Popp A, Erb KH, Lauk C, Harper R, Tubiello FN, Desiqueira Pintok A, Jafari M, Sohi S, Masera O, Bother H, Berndes G, Bustamante M, Ahammad H, Clark H, Dong H, Elsiddig EA, Mbow C, Ravindranath NH, Rice CW, Robledo Abad C, Romanovskaya A, Sperling F, Herrero M, House Jl, Rose S (2013) How much land-based greenhouse gas mitigation can be achieved without compromising food security and environmental goals? Global Change Biology (2013) 19, 2285-2302, doi: 10.1111/gcb.12160

Soussana JF, Tallec T, Blanfort V (2010) Mitigating the greenhouse gas balance of ruminant production systems through carbon sequestration in grasslands. Animal 4(3): 334-35

Thornton PK, Jones PG, Owiyo T, Kruska RL, Herrero M, Kristjanson P, Notenbaert A, Bekele N, Omolo A (2006) Mapping climate vulnerability and poverty in Africa. Report to the Department for International Development, ILRI, PO Box.709, Nairobi 00100, Kenya. Pp 171. Available at: http://www.acts.or.ke/dmdocuments/Mapping Vuln Africa.pdf. Accessed September 2014

Tubiello FN, Salvatore M, Rossi S, Ferrara A, Fitton N, Smith P (2013) The FAOSTAT database of greenhouse gas emissions from agriculture. Environ. Res. Lett. 8015009 doi:10.1088/1748-9326/8/1/015009

TwymanJ, Green M, Bernier Q, Kristjanson P, Russo S, Tall A, Ampaire E, Nyasimi M, Mango J, McKune S, Mwongera C, Ndourba, Y (2014) Gender and Climate Change Perceptions, Adaptation Strategies, and Information Needs Preliminary Results from four sites in Africa. CCAFS Working Paper no. 83. CGIAR Research Program on Climate Change, 
Agriculture and Food Security (CCAFS). Copenhagen, Denmark. Available online at: www.ccafs.cgiar.org. Accessed May 2016

Wheeler S, Zuo A, Bjornlund H (2013) Farmers' climate change beliefs and adaptation strategies for a water scarce future in Australia. Global Environmental Change 23: 537547 